Synthesis of

Heterocycles

\section{Key words}

1,4-benzoxazines

aziridines

2-halophenols

Buchwald-Hartwig cross-coupling

R. K. RAO, I. KARTHIKEYAN, G. SEKAR* (INDIAN INSTITUTE OF TECHNOLOGY MADRAS, CHENNAI, INDIA)

Domino Aziridine Ring Opening and Buchwald-Hartwig Type Coupling-Cyclization by Palladium Catalyst Tetrahedron 2012, 68, 9090-9094.

\title{
A C-O/C-N Coupling Route to 1,4-Benzoxazines
}

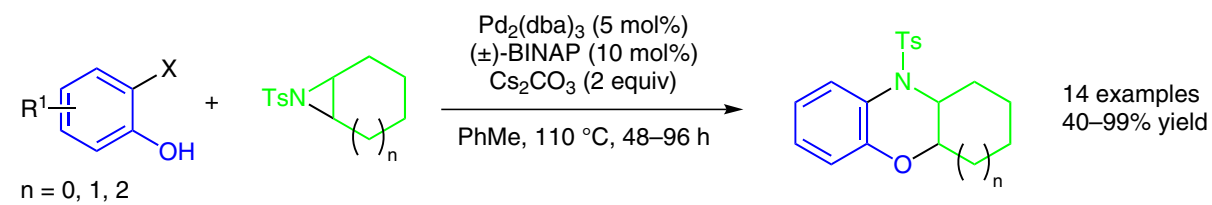

$\mathrm{X}=\mathrm{Cl}, \mathrm{Br}$

$\mathrm{R}^{1}=\mathrm{H}, 4-\mathrm{Me}$, 4-OMe, 4-Cl, 4-Ph

also used was $\mathrm{Ph}$<smiles>CC1CN1[Te]</smiles>

Significance: Reported is the synthesis of substituted 1,4-benzoxazines through a (proposed) domino sequence, initiated by phenol-based aziridine ring opening to expose a tosyl-protected amine which then undergoes Buchwald-Hartwig C-N cross-coupling to provide the observed products. No evidence for this sequence was provided, although it seems reasonable when considered together with previous literature. Of the fused aziridines tested, six-membered rings gave the best results as there was a reduction in yield when moving to five- or seven-membered rings. Slight reductions in yield were observed when moving from electron-neutral 2-bromophenol to those with electron-donating or electron-withdrawing groups. Unsurprisingly, 2-bromophenols performed better than 2-chlorophenols. The use of optically active (S)-BINAP as a ligand gave only partially resolved product.
Comment: 1,4-Benzoxazines are known to have a variety of biologically significant effects and several of these biologically important molecules are shown in the introduction to the current work together with their area of activity. This class of heterocycles has traditionally been synthesized using 2-aminophenols or 2-nitrophenols, both of which can be unavailable and difficult to synthesize if substituted. More modern methods using epoxides as starting materials are also outlined well in the introduction. The method presented above should prove to be a useful and complementary addition to the established methods for 1,4-benzoxazine synthesis in view of the use of readily purchased or easily synthesized starting materials. In addition, the method is operationally simple, uses an inexpensive solvent, and a relatively inexpensive palladium source and ligand. The reaction was optimized with respect to palladium source, ligand, solvent, and base and the substrate scope was modestly examined. 